\title{
DEAF MIDDLE SCHOOL STUDENTS' COMPREHENSION OF RELATIONAL LANGUAGE IN ARITHMETIC COMPARE PROBLEMS
}

\author{
ChongMin Lee ${ }^{1}$ \\ Peter V. Paul ${ }^{2}$ \\ ${ }^{1}$ High School Math Teacher, Metro Deaf School \\ ${ }^{2}$ Department of Educational Studies, The Ohio State University
}

\author{
Original scientific paper
}

Received: 2019/2/9

Accepted: 2019/3/5

\begin{abstract}
This study examined the performance of deaf and hard of hearing middle school students on arithmetic compare word problems with relational statements. Thirteen prelingual, severe-to-profound deaf students were selected to participate. The results showed that the students were more likely to misunderstand a relational statement and make a reversal error when the required arithmetic operation was inconsistent with the statement's relational term (e.g., choosing the operation of addition when the relational term was less than). There were no statistical differences in the number of reversal errors and on lexical markedness (i.e., marked vs. unmarked items). Finally, fraction-of-a-number relational terms exerted more influence on students' abilities to solve word problems than did the lexical markedness. Findings are interpreted in light of the consistency effect hypothesis. Directions for future research and implications for instruction are also provided.
\end{abstract}

Keywords: compare word problems, consistency effect hypothesis, deaf, mathematics

DEAF MIDDLE SCHOOL STUDENTS' COMPREHENSION OF RELATIONAL LANGUAGE IN ARITHMETIC COMPARE PROB-

\section{LEMS}

Middle school (e.g., grades 6 to 8 or 9 in the United States) constitutes a critical juncture when students hone their computational and procedural problemsolving skills, learn advanced inferential reading skills, and master arithmetic operations on whole numbers and fractions, thus laying the foundations for high school algebra and higher-level mathematic abilities (Carpenter, Fennema, Franke, Levi, \& Empson, 2015). During this important timespan of middle school, students need ample practice applying arithmetic operations (i.e., addition, subtraction, multiplication, and division) and solving word problems with whole numbers and fractions so they can use this knowledge base for the comprehension and solution phases of more complex word problems with relational language in high school and postsecondary education (Lewis \& Mayer, 1987).

\footnotetext{
Correspondence to:

${ }^{1}$ ChongMin Lee, PhD, High School Teacher, Metro Deaf School, 1125 Energy Park Drive, St Paul, MN 55108

Email: clee@mdsmn.org

${ }^{2}$ Peter V. Paul, PhD, The Ohio State University

Email: paul.3@osu.edu
} 
One type of word problem with relational language, the compare word problem, particularly challenging for deaf and hard of hearing (DHH) students often leading them to an incorrect solution because of experiential, language, and reading gaps, particularly those related to the use of inference skills (Pagliaro, 2010; 2015). Even typical hearing children find solving the compare word problem to be cognitively demanding (Carpenter et al., 2015; Lewis \& Mayer, 1987). As such, compare word problems require the problem-solver to read the word problem and contrast differences of unknown quantities while comprehending more complex sentence structures with relational terms. Other word problems such as the combine (unknown quantities increase) and change word problems (unknown quantities decrease) are relatively easier to solve as the relational terminology provides a consistent clue (more means addition; less means subtraction, etc.) rather than obstructs understanding as seen with word problems with inconsistent language (more than means subtraction, less than means addition) (Carpenter et al., 2015). Relational terminology not only requires linguistic understanding of the problem-solver to "read between the lines" or infer the meaning of the story posed in the problem, but also the student needs to have the mathematical knowledge to construct a mental model of what is being asked in order to figure out and infer values to either increase or decrease between two or more unknown quantities. Relational terms such as more, less, $n$ times as many, including fraction-of-a-number terms $1 / n$ as many, add complexity to solving word problems (Pape, 2003).

The complexity of solving word problems has not gone unnoticed by professional societies. The Common Core State Standards (CCSS) [in the United States] curriculum addressed this issue. "Students need to make conjectures about the form and meaning of the solution and plan a solution pathway rather than simply jumping into a solution attempt" (CCSS, 2013 , p. 6). DHH students have difficulties with solving word problems as shown by their low performance on mathematic achievement tests. Specifically, Traxler (2000) found that $80 \%$ of American DHH students in grades four and eight performed at the 'basic' or 'below basic' level in both procedural performance and word problem solving. Furthermore, Traxler found that half of the fourth graders fell below a third grade level in procedures and at a second grade level in problem solving with the eighth graders scoring at a fourth grade level in both areas (Traxler, 2000 cited in Pagliaro, 2010, p. 157).

To address this challenge, the purpose of the present study was to examine the performance of American DHH middle school students on arithmetic compare word problems with relational statements, including those with fractions. Fractions were included as studies have shown that DHH students lack basic understanding of fractions, specifically with calculations and understanding of order and equivalence (Titus, 1995), with concepts related to part-to-whole (Kelly \& Mousley, 2001; Markey, Power, \& Booker, 2003), with placement in order from smallest to the largest (Mousley \& Kurz, 2015), with comprehending the relationship between fractions and ratios (1:3 and 1:4) (Nunes \& Moreno, 2002) as well as with understanding of fractions when they are embedded in compare word problems (Lee, 2010). The next section reviews previous studies related to math abilities and word problems for DHH and typical hearing students.

\section{LITERATURE REVIEW}

\section{DHH Students and Math Word Problems}

Relational language. Understanding the difficulty $\mathrm{DHH}$ students have in solving word problems is multifaceted. For example, they often have few experiences with solving story problems with relational language such as the use of comparatives in phrases such as more than, less than, faster than three times as many as, half the number (Serrano Pau, 1995; Zenvenbergen, Hyde, \& Power, 2001). Some studies demonstrated that these deficits begin early (Pagliaro, 2015; Pagliaro \& Kritzer, 2013).

Emergent math literacy. Multiple studies have shown that DHH students experience a "math knowledge gap" compared to typically-performing hearing students (Pagliaro, 2015; Qi \& Mitchell, 2012; Traxler, 2000) which can be traced back as early as the emergent math skills stage in preschool and kindergarten. Further, DHH students lack the tools to solve arithmetic word problems due to their infrequent informal math experiences or math readiness in the home with counting and measuring skills, their inability to understand non-linguistic number representations, and their low performance in computing basic arithmetic operations (Ansell \& Pagliaro, 2006; Kritzer, 2009; Pagliaro \& Kritzer, 2013; Zarfaty, Nunes, \& Bryant, 2004). 
Teacher and peer conversations about math concepts. Researchers reveal that teacher and peer conversations about arithmetic concepts are sorely needed as shown in an ethnographic study of three first-grade deaf education classrooms in Colombia, South America. Based on observations of teacher-student interactions while teaching mathematics, Corredor and Calderon (2010) gathered data on the math learning communication skills, social language in math concept development, and the importance of sign bilingualism (Colombia Sign Language or LSC and Spanish). The researchers noted that first grade students did not understand even basic aspects of counting such as one-to-one correspondence or ordinal, and cardinal numbers. Furthermore, the researchers observed that students had few opportunities for math exploration because they had no tools such as computers, calculators, and other math support devices. Researchers also discovered that the math teachers and even the deaf tutors and educational interpreters had limited mathematical professional training. Many of the teachers could not communicate with the children, and did not know sign language. Even when they had a deaf tutor or educational interpreter, this was still not enough because it did not provide children with in-depth interactive conversations about mathematical processes and reasoning (Corredor \& Calderon, 2010).

Early elementary levels. Without these deep and extended conversations about math concepts, the "math gap" continues to widen as DHH students progress through the early elementary grades (Zarfaty, Nunes, \& Bryant, 2004), with gaps in math understanding even following them into middle school (Lee, 2010). Notwithstanding that DHH students have visual strengths to assist them with counting and memory (Zarfaty et al., 2004), these skills do not always transfer to solving word problems in elementary school (Ansell \& Pagliaro, 2006). To illustrate, Zarfaty and colleagues compared DHH and hearing children $(n=10, \mathrm{DHH} ; \mathrm{n}$ $=10$, hearing) who were between 31 and 54 months old on their ability to count and to remember a series of objects. Comparing presentations in a spatial array with a temporal array, the researchers found that young DHH students outperformed their hearing age-mates on the spatial array and performed as just as well on the temporal array. The researchers hypothesized that spatial strength may be a promising instructional strategy for teaching DHH preschoolers logic and counting as well as to develop informal problem-solving strategies. However, in a follow-up study, Ansell and Pagliaro (2006) found that young DHH children in K-3 grades did not carry over these visual-spatial strengths in solving story problems. Instead the children focused on the numbers, ignoring what the story was asking of them. In this experiment, 59 DHH children in K-3 grades from nine schools for deaf students were administered several instruments to assess story problem solving strategies. The DHH students were given six story problems to solve that had been translated into American Sign Language (ASL). Younger students were more likely to use counting strategies rather than focus on the meaningful language in the story problems even when presented the story problems in their dominant language, ASL. Thus, researchers concluded that while translating the story problems into ASL does break down the English language barrier, the teachers could not depend on translation alone to ensure the young students understand the underlying arithmetic concepts and relations to arrive at the correct solution.

Math concepts. Underlying the understanding of word problems is comprehending mathematical concepts. Kritzer (2009) highlighted the importance of math concepts in her investigation of DHH preschool and kindergarten students' early informal/formal mathematical knowledge. Utilizing the Test of Early Mathematics Ability (TEMA-3), she tested 29 children ages 4 to 6 years of age from seven schools for deaf children. Kritzer found that $60 \%$ of her sample were experiencing delays with math concepts related to story problems, counting, number comparisons, the reading/writing of two to three digit numbers, and addition and subtraction facts (Kritzer, 2009).

Compare word problems. Compare word problems are even more challenging for young DHH students (Ansell \& Pagliaro, 2006; Pagliaro \& Ansell, 2012; Serrano Pau, 1995; Zeverbergen, Hyde, \& Power, 2001). In an early study with 12 young elementary DHH students in Spain, Serrano Pau (1995) examined comprehension across three types of arithmetic word problems-change, combine, and compare problems. With change problems an unknown quantity is decreased and with combine word problems the unknown quantities increase. See Table 1 for the three types, definitions, and examples of combine, change, and compare story problems and Table 2 for the four types of compare word problems with consistent/inconsistent language and unmarked and marked lexical markedness. 
Table 1. Types, Definitions, and Examples of Word Problems (adapted from Carpenter et al., 2015; Hyde, Zevenbergen, \& Power, 2003; Riley et al., 1984).

\begin{tabular}{|c|c|c|c|}
\hline & Types & Definition & Example \\
\hline 1 & $\begin{array}{l}\text { Change (separate) } \\
\text { (Unknown small } \\
\text { quantity) }\end{array}$ & $\begin{array}{l}\text { Questions that involve a process } \\
\text { whereby there is an event that alters the } \\
\text { value of the quantity. }\end{array}$ & $\begin{array}{l}\text { Peter had three oranges. Michele gave him } 2 \text { more } \\
\text { oranges. How many oranges does Peter have now? }\end{array}$ \\
\hline 2 & $\begin{array}{l}\text { Combine (Join) } \\
\text { (Unknown big quantity) }\end{array}$ & $\begin{array}{l}\text { Questions that relate to static situations } \\
\text { in which there are two amounts. These } \\
\text { are considered either as separate entities } \\
\text { or in relation to each other. }\end{array}$ & $\begin{array}{l}\text { Sarah has } 4 \text { oranges; Michele has } 2 \text { oranges. How } \\
\text { many oranges do they have together? }\end{array}$ \\
\hline 3 & $\begin{array}{l}\text { Compare } \\
\text { (Difference unknown) }\end{array}$ & $\begin{array}{l}\text { Questions that involve the comparison } \\
\text { of two amounts or quantities and the } \\
\text { difference between them. }\end{array}$ & $\begin{array}{l}\text { Ben has } 5 \text { oranges. Alice has } 2 \text { more oranges than } \\
\text { Ben. How many more oranges does Alice have } \\
\text { than Ben? }\end{array}$ \\
\hline
\end{tabular}

Table 2. Four Types of Arithmetic Word Problems with Consistent Language and Inconsistent Language and with Unmarked and Marked Lexical Forms (adapted from Hegarty, Mayer \& Green, 1992)

\begin{tabular}{lll}
\hline \multicolumn{1}{c}{ Relational Term } & \multicolumn{1}{c}{ Consistent Language } & \multicolumn{1}{c}{ Inconsistent Language } \\
\hline Unmarked "more" & At Kroger water sells for \$1.11 per gallon. & At Kroger water sells for \$1.11 per gallon. \\
& $\begin{array}{l}\text { Water at HEB is } 4 \text { cents more per gallon than at } \\
\text { Kroger. }\end{array}$ & This is 4 cents more per gallon than water at HEB. \\
& $\begin{array}{l}\text { If you want to buy } 5 \text { gallons of water, how much } \\
\text { will you pay at HEB? }\end{array}$ & $\begin{array}{l}\text { If you want to buy } 5 \text { gallons of water, how much } \\
\text { will you pay at HEB? }\end{array}$ \\
\hline Marked "less" & $\begin{array}{l}\text { At Kroger water sells for \$1.11 per gallon. } \\
\text { Water at HEB is } 4 \text { cents less a gallon than water at }\end{array}$ & $\begin{array}{l}\text { At Kroger water sells for } \$ 1.11 \text { per gallon. } \\
\text { This is } 4 \text { cents less per gallon than water at HEB. }\end{array}$ \\
& $\begin{array}{l}\text { Kroger. } \\
\text { If you want to buy } 5 \text { gallons of water, how much } \\
\text { will you pay at HEB? }\end{array}$ & $\begin{array}{l}\text { If you want to buy } 5 \text { gallons of water, how much } \\
\text { will you pay at HEB? }\end{array}$ \\
\hline
\end{tabular}

Serrano Pau found that DHH students in elementary school were better able to solve a word problem if the relational term (e.g., more than, less than) was consistent or the same as the operation required to solve the problem. To illustrate this concept, consider this 3 -sentence two-step math word problem with consistent language. For clarification, a one-step word problem requires the student to have only one step to solve a word problem with one equation whereas a two-step word problem requires the student to solve two different equations before coming to the answer with two different operations such as multiplication and addition, or two of the same operation such as using subtraction twice (https://study.com/academy/ lesson/two-step-math-word-problems.html)

In the Serrano Pau study, students responded by simply ignoring the comparative linguistic terms or they would simplify the comparative form of "have more than" to "have", and this resulted in an misinterpretation of the task. Young DHH students were given 8 word problems individually which they read and solved on paper. 
Overall, the results showed that children's higher reading comprehension abilities, tested on a standardized measure, resulted in better problem-solving abilities, but they still experienced difficulty with comprehending relational language, particularly if the language was inconsistent with the operation and the relational term.

In another study, Zevenbergen and his colleagues (Zevenbergen et al., 2001; Hyde, Zevenbergen \& Power, 2003) tested 78 deaf Australian students who were moderately to profoundly deaf and who were enrolled in grades 1 to 12 . Students were given a set of 24 word problems to solve across three word problem types: change, combine, and compare (Please refer again to Table 1). Targeted students from each age group were interviewed using the "think-aloud" procedure. The "think-aloud" is a research methodology that uses verbal reports as data in which the experimenter asks a student to report about how he or she is comprehending. In the Zevenbergan et al.'s study, transcribed strategies "indicated a restricted understanding of the intricacies of mathematical language" and "an overreliance on trigger words" (p. 213). Trigger words are keywords in a word problem that triggers the student to focus on an operation (e.g., more triggers addition; less triggers subtraction). Furthermore, researchers found that deaf students had greater difficulty in solving word problems with the relational term, less than. Students misunderstood the term less as take away to always mean subtraction and to look for numbers lesser in value in the problem. Similarly, students overgeneralized the term more to mean addition. The term, than, was often overlooked or ignored by the students leading to misinterpretation of the word problems similar to Serrano Pau's (1995) finding with elementary DHH students. Furthermore, the researchers found DHH students had more difficulty with compare word problems that required a comparison and a difference (Please see Table 1 again). These results showed that students had better performance on change problems than on the combine and the compare problems particularly among the younger DHH students who had less experience with English and mathematics. The researchers found that comparative linguistic expressions were difficult for all reading and math levels of students.

More recently, researchers have investigated DHH students' comprehension of compare word prob- lems when they are translated into ASL (Ansell \& Pagliaro, 2006; Pagliaro \& Ansell, 2012). These researchers tested $59 \mathrm{DHH}$ children in K-3 settings from ages 5 to 9 years of age who attended schools for deaf students in the United States. Six story problems were translated into ASL. The story problems represented the operations of addition and subtraction. The results on the compare word problem (difference unknown) showed significantly less strategy usage by the children. The word problems that required combining or joining or separating elements were easier than the compare word problems with a difference being unknown. The majority of the students over-relied on a "counting strategy."When using the counting strategy, the students would take one of the quantities (a number) in the problem and continue counting a sequence from the first number to the other quantity (number), then use "trigger" or "key" words such as more and use the operation of addition or see the word less and use subtraction (Ansell \& Pagliaro, 2006; Pagliaro \& Ansell, 2012).

Mathematics language. The difficulty found with mathematics vocabulary that is embedded in relational language statements has been found to be challenging for even high math functioning DHH high school students (Kidd, Madsen, \& Lamb, 1993). These researchers used the terminology words with special emphasis in mathematics to signify a particular type of vocabulary that is problematic for DHH students. For example, Kidd and her colleagues identified phrases such as how many, how many more, how many less and defined them as vocabulary that had subtle meanings in word problems that were different in meanings than these same words in everyday usage.

In this study, researchers tested $25 \mathrm{DHH}$ students in grades 9 to 12 who were academically in the top two ability groupings and used ASL and Signed English as their preferred mode of communication. A 50-item multiple-choice test was constructed and the content consisted of five categories of mathematics vocabulary found in word problems in middle school textbooks. The vocabulary that was selected consisted of words with more than one meaning (e.g. square), technical vocabulary (e.g., sine, polynomial), varied forms (e.g., multiply, multiplicand, multiplication), abbreviations and symbols, and words with special emphasis in mathematics. 
The researchers noted "The scores decline in the section on words with special math emphasis in mathematics" (p. 420). They further commented that these words are seen in everyday life; as multiple meaning words, they take on a different meaning when embedded in math word problems, hence they create comprehension difficulty related to mathematics learning (Kidd et al., 1993).

English grammar challenges. Deafness can obstruct the learning of spoken and written English (Paul, 2009), and this carries over into math word problems in the areas of both vocabulary and syntax. To illustrate syntax difficulties, consider this word problem provided by Zevenbergen et al. (2001, p. 216): John has 2 buckets. Eric has 6 buckets. How many more buckets than John does Eric have? The final sentence requires a comparison to be made and a difference calculated. Even to the native English user, this word problem requires careful reading of each individual sentence, making note of what is being asked, visualizing a mathematical representation, and choosing the correct operations in order to arrive at a correct solution. Zevenbergen and his colleagues found that DHH students "jumped to a fast solution" by zeroing in on the word, more and interpreting it to mean-- simply adding the 2 numbers (6 and 2) to arrive at the incorrect solution of " 8 ." The researchers found other students simply overlook and ignore the term than and answer " 6 ." Both strategies led to incorrect solutions. Zevenbergen and his colleagues concluded that DHH students had difficulty with word problems due to both the syntax of the question and choosing the correct arithmetic operations.

Even when vocabulary and syntax were eliminated and substituted with animated computer games, as Frostag and Ahlberg (1999) attempted in their study, DHH students still had conceptual difficulties with understanding word problems. The experimenters followed up with a paper task where the DHH students retold the subtraction word story problem then chose the correct answer using a picture/number format. Thirty two Norwegian DHH children with varying hearing levels from less than severe to profound in K-4 grade were selected. All used Norwegian Sign Language (NSL) and had basic counting skills. After being administered a set of change word problems, the students were interviewed about their strategies. After the rate of correct solutions were computed and strategies categorized, the results showed that DHH students did not know how to approach word problems thoughtfully. Norwegian DHH students simply focused on the numbers in which they combined or subtracted them without any logical reasoning, a finding similar to those of Ansell and Pagliaro (2006) and Zevenbergen et al. (2001) who also found DHH students were focused on numbers and not on mathematically, logically-driven solutions.

Other grammar obstacles. Relational terms and pronominal references were found to be additional grammatical obstacles for DHH students in high school in England. Swanwick, Oddy and Roper (2005) studied the scores and error patterns of 126 DHH students who were 14 years old and who were administered the National Curriculum Test in Mathematics. They found that DHH students had difficulty with phrases such as more than and less than and also had difficulty with comprehending the linguistic structure of referential pronouns on math word problems. The researchers noted, “... one literacy problem experienced by deaf pupils is that of following the connected meaning of a written passage, as they often find it difficult to make sense of pronouns (its, that, he, the) when they are disconnected from the object or person to which they refer to" (p. 11). Swanwick and her colleagues (2005) attributed this difficulty to the effects of deafness on auditory short-memory and its role in processing written language.

Postsecondary DHH students. Studies have shown that the ability to solve word problems does not increase as students progress into postsecondary school. Similar to young DHH students, university students also exhibited difficulty with finding solutions to word problems because of reading comprehension level, computation errors, procedural errors, or even motivational factors. Sometimes they would simply leave the word problem blank and not attempt any solution at all. One might assume that as DHH students become older, had more language and more math computational and problem solving experiences, they would be able to self-monitor their progress. However, researchers found the reverse to be true. Findings showed that DHH students neither had the computational skills, problems solving skills, nor knew how to self-correct while finding solutions to word problems (Kelly, Lang, Mousley, \& Davis, 2003; Kelly \& Mousley, 2001). 
While controlling for language, reading, and computational skills, Kelly and Mousley (2001) found that DHH students made numerous errors with the word problem format, and these errors included leaving the problem blank, making computational errors, and making procedure errors. These researchers tested $44 \mathrm{DHH}$ college students who were grouped according to reading level (low, middle, high) after taking the California Achievement Test for Reading Comprehension. DHH students were given 30 mathematical word problems presented under the number/picture only condition (n $=15)$ and word only condition $(\mathrm{n}=15)$. DHH students were able to solve the computations in word problems presented in the visual format (pictures and numbers), but were not able to solve the word problems when language was added.

In another study with DHH postsecondary students, Kelly et al., (2003) examined a more complex aspect of word problems, that of relational language with consistent language and with inconsistent language. In this study, 80 university level DHH students were tested on reading comprehension using the California Achievement Test for Reading Comprehension. Based on their performance, the students were divided into four groups from low to high ability readers. Using materials developed by Lewis and Mayer (1987), students were given 8 target arithmetic compare word problems with filler problems for a total of 32 word problems. Filler problems are ones that do not follow the same format as the word problems being tested. The average grade level readability of the text per problem was 3.6 and ranged from 3.2 to 5.4 for the 32 problems.

The DHH students, regardless of reading ability, correctly solved more consistent word problems than inconsistent word problems, thus supporting Lewis and Mayer's (1987) consistency effect model. The researchers extended this model by finding that the reading ability levels of the DHH students did not influence performance on word problems with inconsistent language. The results showed that all students produced a higher percentage of reversal errors on inconsistent language problems than on consistent language problems, regardless of their reading level. That is, the consistency effect was not affected by reading level, although the researchers reported that fewer reversal errors were produced by the high reading group on both sets of problems.

Teacher-preparation practices. Teachers can play a critical role in mathematics instruction if they are adequately trained, provide cognitively demanding math instruction, and have high expectations (Pagliaro,
2015). Kelly, Lang, and Pagliaro (2003) sent out a survey to 133 teachers in grades 6 through 12 where 50 percent worked at center schools and 50 percent in mainstream programs. They found that teachers typically did not provide DHH students with cognitively challenging mathematical situations to solve in a word problem format. Many survey respondents did not have university math preparation coursework. Moreover, teachers had low expectations due to DHH students' underdeveloped language proficiencies. Teachers were neither academically prepared nor equipped to teach DHH students how to develop concepts about mathematical representations, but instead focused on practice exercises rather than true problem solving strategies. While teachers focused frequently on visualization strategies to capitalize on DHH students' visual strengths (see Kritzer, 2006, for similar results), they did not adequately teach students how to mentally represent mathematical relationships necessary to becoming a successful problem solver. Teachers also lack university preparation in mathematics with few having mathematics teaching certification. Those teachers who were certified, however, were found to use more challenging, analytical strategies for word problem solving.

\section{Typical Hearing Students and Math Word Prob- lems}

Compare word problems. Similar to DHH children, those with typical hearing levels, as early as the first grade, may be able to solve problems in numeric formats. However, when problems are presented in a word format, they have difficulty solving them (Cummins, Kintch, Reusser, \& Weimer, 1988). Furthermore, first graders have an easier time solving combine and change word problems, than solving compare word problems where they have to understand not only the unknown quantity, but also the relationship between the numbers in the word problem. With older students in elementary and middle school, Carpenter, Corbitt, Kepner, Linquist, and Reys (1980) found that, among 9 to 13 year old children in the United States, most did well on numeric format calculations, but 10 to 30 percent did worse when solving compare arithmetic word problems.

Consistency Effect Hypothesis. Lewis and Mayer (1987) devised their consistency effect hypothesis and have utilized this abstract representation to explain how students solve compare word problems with populations ranging from elementary to postsecondary levels. 
According to this model, students possess their own schema or preference concerning the form in the statements, then they rearrange the information but arrive at an incorrect answer by imposing their own order of information on the problem rather than comprehending what is actually being demanded of them. This theory explains why students have more difficulty with solving problems with relational statements that are inconsistent with the arithmetic operation. Furthermore, Lewis and Mayer posited that both the inconsistent and consistent language problems produce different error rates.

Hearing college students. Lewis and Mayer (1987) studied 96 hearing college students who were assessed across 8 word problem types. These researchers described the difference between consistent and inconsistent language problem types. They identified three error categories: reversal errors (RE), arithmetic errors (AEs), and goal monitoring errors (GMEs). The researchers reported that students solved word problems with a preconceived expectation on how the statements should be ordered, and this partly explained their reversal errors in the compare word problems with inconsistent language. They also reported that hearing college students are more likely to miscomprehend a relational statement in an inconsistent word problem and made a reversal error (incorrect arithmetic operation) when the relational term was marked (e.g., less than).

Lewis and Mayer (1987) emphasized the salience of the terms "less" and "more" or " $1 / \mathrm{n}$ as many" in inconsistent multiplication problems as the cause for the greater number of errors in solving word problems. Students were found to be more likely to misunderstand a relational statement in a word problem with inconsistent statements and make reversal errors depending on the lexical marker of the statement (Lewis \& Mayer, 1987). Herbert Clark, a psycholinguist argued that unmarked positive adjectives (e.g., more) are stored in the memory in a less complex form than those of their negatively marked (e.g., less) opposites (cited in Kelly et al., 2002). In other words, unmarked positive terms like the word more are easier to process and comprehend than marked negative words like less. Students who are solving word problems with a marked negative term in the inconsistent relational statement (e.g., less in addition problems or $1 / n$ as many in multiplication problems) will produce more reversal errors. On the other hand, Kelly explained that students can more easily process a compare word problem with an inconsistent relational statement with an unmarked term (e.g., more in subtraction problems and $n$ times as many in division problems) resulting in fewer reversal errors.

Lewis and Mayer (1987) also suggested that the larger number of errors on inconsistent multiplication problems may be from the complexity of the underlying mathematical concept contained in word problems with fraction-of-a-number terms, and this may impede students' comprehension more often than the lexical markedness of the term. With inconsistent language word problems, students tend to make reversal errors by failing to choose the correct arithmetic operation for the correct solution.

Other researchers have extended the findings of Lewis and Mayer's model (1987) by developing experiments utilizing hearing students at various ages (college, junior high, elementary) with different methodologies such as eye-tracking, think-a-loud, or verbal reports, and retellings. As such, Verschaffell, De Corte, and Pauwells (1992) conducted three eye-movement experiments where they collected performance data, response times, and eye movements of participants while reading and solving word problems. In the first experiment, 19 hearing college students solved 30 one-step addition and subtraction compare word problems, which included 8 consistent and 8 inconsistent language forms. This experiment did not support the Lewis and Mayer's model, and the eye-fixation data revealed that students did not need more time with the word problems with inconsistent language. Data in the second experiment with 15 students in the third grade students who were administered 26 one-step addition and subtraction problems did support the model.

In the third experiment, 20 college students were given 24 two-step compare problems, half contained the consistent language form and half the inconsistent language form. Students produced more reversal errors solving the inconsistent language problems than with consistent language problems. The researchers concluded that the Lewis and Mayer's model is supported only with word problems with inconsistent language that put heavy cognitive and linguistic demands on the participants.

In another study, Hegarty, Mayer, and Monk (1995) also used eye-fixation data and memory data to examine performances. Success was defined as arriving at the correct answer. Thirty-eight college students participated and took a test of 48 compare arithmetic word problems with consistent and inconsistent language forms. Unsuccessful word problem solvers needed more time and utilized the "direct translation" (also called key-word) approach. 
Hegarty has defined the "direct translation" or "short-cut" approach; this means that the problem solver tries to select the numbers in the problem and key relational terms, then develops a solution that involves combining the numbers and applying the arithmetic operation that is primed by key words (e.g., addition if keyword is "more" and subtraction if it is "less"). In contrast to this surface structure strategy is the "meaningful approach" where the successful problem-solver translates the problem statement into a meaningful mental model of the events presented in the problem.

In still another study, Hegarty, Mayer, and Green (1992) examined 32 college students' eye-fixations as they read arithmetic word problems with consistent and inconsistent language forms on a computer monitor and verbally stated a solution plan for each problem. Least skilled math students made more reversal errors on inconsistent and consistent problems. Here students needed more time for word problems that had inconsistent language. More skilled problem solvers fixated longer or needed more time in the problem model and solution plan rather than during the reading stage. More skilled math students also needed more time to reread previously fixated words for inconsistent than for consistent problems. When using the superficial strategy of the direct translation approach, students were not able to visualize a situational model for the problem. The researchers found that the most successful word problems solvers, that is, those who arrived at the correct answers, focused on variable names and relational terms so they could formulate a meaningful mental model of the problem. Pape $(1998,2003)$ studied 106 students in sixth to ninth grade who read, solved, and recalled oneand two-step addition, subtraction, multiplication, and division compare word problems. Using thinkaloud protocols and recall data, Pape provided strong support for the consistency effect hypothesis. In other words, the data showed that problem solvers are likely to translate inconsistent language problems to problems that better match their schema. Students made more reversal errors (used an opposite operation) on inconsistent language than consistent language problems, recalled inconsistent language as consistent language, and inverted the relational sentence during recall more often following a reversal error. Differences were not found for number of rereadings, or total response time, and quality of recall. Most students used the "direct translation" approach without thinking through the solution. Students committed more errors overall and reversal errors specifically (using the opposite operation) on inconsistent language forms than on consistent language forms and recalled inconsistent language forms as consistent problems, making reversal errors.

Pape also found that junior high students had difficulty forming representations and solving problems involving fraction-of-a-number constructions. Fraction-of-a-number indicates the relationship between part and whole. Students are asked to thinkaloud while reading, solving, and recalling one and two-step addition, subtraction, multiplication, and division compare word problem. Lewis and Mayer's (1987) consistency hypothesis was examined by comparing problem solving success, patterns of errors, problem-solving behaviors, number of rereadings, initial reading time, total response time, quality of problem recall, and recall reversals for consistent language and inconsistent language problems. The think-aloud stimulus of 16 mathematics word problems included 12 target word problems with two step and one step procedures for a total of 960 word problems. Most students used the direct translation $(69 \%)$ than meaningful approach (31\%). The largest number of errors were reversals and fraction-of-a-number errors with linguistic and computational errors found less frequently in this sample.

Utilizing a younger sample, Verschaffell (1994) tested the consistency effect hypothesis with 40 fifth-graders who were 10 to 11 years old and who were asked to solve and retell a set of one-step compare problems. The retelling technique of a word problem is not just memorizing and reproducing, but requires the student to construct or rebuild the problem from the mental representation that she has generated after reading the problem and before choosing the arithmetic operation. Students were given nine one-step addition and subtraction word problems, one warm up problem, and four compare problems (two with consistent language structure; two with inconsistent language structure). Students solving consistent language problems chose more correct arithmetic operations, were faster in solving the problems, and had more correct retelling protocols, compared to their performance on inconsistent language problems. 


\section{RATIONALE FOR THE PRESENT STUDY}

While other studies with hearing and DHH students as reported above examined compare problem solving, relational language, and fraction-of-a-number terminology, none focused specifically on DHH students in junior high who used a signed language as their primary language. The present study also provides a test of the consistency effect hypothesis for DHH students in junior high school (grades 7 to 9).

\section{HYPOTHESES}

Three hypotheses were tested.

$\mathrm{H}_{1}$ : Compare word problems that have relational statements consistent with the arithmetic operation will result in more correct answers than word problems having relational statements that are inconsistent with the arithmetic operation.

$\mathrm{H}_{2}$ : With compare word problems, those having negative marked terms and positive marked terms will be equally difficult, and there will be no difference in students' performance on producing reversal errors.

$\mathrm{H}_{3}$ : More errors will occur with word problems containing fraction-of-a-number relational terms than on problems without such relational terms.

\section{METHODOLOGY}

\section{Participants}

Sampling procedure. A purposive sampling procedure was utilized. By definition, "The purposive sampling technique, also called judgment sampling, is the deliberate choice of a participant due to the qualities the participant possesses" (Etikan, Musa, $\&$ Alkassim, 2016, p. 2). Purposive sampling is useful when randomization is not possible. Since deafness is considered to be a low-incidence disability, large groups of DHH students in junior high are difficult to locate in one central setting except for state schools for deaf students. To this end, students were selected from a residential school which centralizes a larger number of deaf students. Financial resources were not available to test deaf students at multiple sites with smaller numbers of DHH student enrolled in mainstream programs. Thus, the researchers purposively located a suitable group of middle school deaf students in one residential school.

Background survey. The survey was designed to examine students' characteristics including age, grade, communication mode, pure-tone averages (PTAs), and standardized test scores in English reading and mathematics. The PTAs, reading, and mathematics scores were obtained from the students' records in the school administration office after University's Institutional Review Board (IRB) approval.

A total of 16 deaf students located in a school in the middle-eastern region of the United States were initially recruited. Students were selected based on the following criteria: hearing loss in the severe to profound range, as this is the range that is most vulnerable to access and acquisition of spoken and written English (Paul, 2009). Students were in junior high school or seventh to ninth grade and were between the ages of 10 and 16 years, inclusive. Deafness occurred prior to language being developed (i.e., prior to age 3 ). No additional educational or learning disabilities were present, and the students must be willing to participate.

Of the 16 students, three students were excluded for data analysis due to incomplete responses, leaving 13 students. Participants ranged in age from 10.2 to 16.6 years, with a mean age of 13.51 years, and spanned grade levels seven through nine. One student from the 4th grade was included because her teacher believed that she would be able to solve word problems. The reading levels of participants ranged from 2.5 to 8.5 grade with a mean of 5.33; math level ranged from 4.10 to 8.40 grade with a mean of 5.97. See Table 3. 
Table 3. Characteristics and Language Backgrounds of Participants

\begin{tabular}{|c|c|c|c|c|c|c|}
\hline$\#$ & Grade & Age & PTA & Communication/language use at home & Math & Reading \\
\hline 1 & $7^{\text {th }}$ & 13.6 & $\begin{array}{l}\mathrm{L}: 120 \\
\mathrm{R}: 120\end{array}$ & Signed English & 8.4 & 5.5 \\
\hline 2 & $7^{\text {th }}$ & 14.8 & $\begin{array}{l}\mathrm{L}: 87 \\
\mathrm{R}: 87\end{array}$ & Few signs & 7.2 & 4.0 \\
\hline 3 & $7^{\text {th }}$ & 14.3 & $\begin{array}{l}\mathrm{L}: 105 \\
\mathrm{R}: 107\end{array}$ & Signed English & 4.2 & 3.0 \\
\hline 4 & $7^{\text {th }}$ & 13.8 & $\begin{array}{c}\mathrm{L}: 103 \\
\mathrm{R}: 70\end{array}$ & Spoken & 4.1 & 2.5 \\
\hline 5 & $7^{\text {th }}$ & 14.6 & $\begin{array}{l}\mathrm{L}: 107 \\
\mathrm{R}: 107\end{array}$ & ASL & 7.5 & 5.0 \\
\hline 6 & $8^{\text {th }}$ & 13.7 & $\begin{array}{c}\mathrm{L}: 108 \\
\mathrm{R}: 88\end{array}$ & Signed English/Spoken & 5.9 & 5.5 \\
\hline 7 & $4^{\text {th }}$ & 10.2 & $\begin{array}{l}\text { L:108 } \\
\text { R:120 }\end{array}$ & Signed English/Spoken & 5.1 & 4.5 \\
\hline 8 & $9^{\text {th }}$ & 15.10 & $\begin{array}{l}\mathrm{L}: 82 \\
\mathrm{R}: 83\end{array}$ & Few signs/writing & 7.1 & 8.5 \\
\hline 9 & $9^{\text {th }}$ & 16.4 & $\begin{array}{l}\mathrm{L}: 120 \\
\mathrm{R}: 102\end{array}$ & Few signs & 5.7 & 7 \\
\hline 10 & $9^{\text {th }}$ & 15.11 & $\begin{array}{c}\text { L:93 } \\
\text { R:102 }\end{array}$ & Few signs & 6.7 & 5 \\
\hline 11 & $9^{\text {th }}$ & 15.6 & $\begin{array}{l}\text { L:93 } \\
\text { R:92 }\end{array}$ & Signed English & 5.9 & 8 \\
\hline 12 & $9^{\text {th }}$ & 16.6 & $\begin{array}{l}\mathrm{L}: 105 \\
\mathrm{R}: 103\end{array}$ & ASL & 5.7 & 8.5 \\
\hline 13 & $9^{\text {th }}$ & 16.6 & $\begin{array}{c}\mathrm{L}: 103 \\
\mathrm{R}: 77\end{array}$ & Signed English & 8.4 & 7 \\
\hline
\end{tabular}

Note: $\quad$ PTA $=$ pure tone average

$\mathrm{L}=$ left ear

$\mathrm{R}=$ right ear

$\mathrm{ASL}=$ American Sign Language

\section{Materials}

Math word problems. A set of compare word problems drawn from Pape's study (1998) with hearing middle school students in the 5th and 6th grade were utilized in the present study. The new Dale-Chall readability formula (Chall \& Dale, 1995 as cited in Kelly et al., 2003) indicated that the readability levels of the word problems utilized in the present study was between 4th grade and 5 th grade. There were 16 word problems, including 12 target problems and 4 filler problems. The four filler word problems also have the same word problem structure, but were not compare word problems with relational terms. The filler problems were used to minimize any stereotyped responses and to provide variation in the types of problems students were solving (Pape, 1998). Filler problems were excluded from the data analysis.
The twelve target word problems were composed of six consistent and six inconsistent language problems. Eight of them were two-step consistent language and inconsistent language problems that required four arithmetic operations (i.e., addition, subtraction, multiplication, and division). The remaining four problems were two one-step consistent language and inconsistent language problems that required multiplication and division operations only (Pape, 1998). Additionally, these problems contained a fraction number of relational term that required fractional knowledge to solve the problems. According to the teachers of the participants in the present study, these problems were representative of the types of mathematics problems in the textbooks at the middle-school grade level. The adaptation of the original tasks (Pape, 1998) involved only a change in the names of stores to minimize the effects on problem-solving performance. For example, Arco or Pathmark stores were replaced with $B P$ or Kroger, which were familiar to the students. See Table 4. 
Table 4. Types of Problems and Solution Steps for Consistent Language and Inconsistent Language Word Problems (adapted from Pape, 1998; 2003)

\begin{tabular}{|c|c|c|c|c|}
\hline Problem statement & $\begin{array}{l}\text { Number of } \\
\text { solution steps }\end{array}$ & $\begin{array}{l}\text { Types of } \\
\text { problems }\end{array}$ & $\begin{array}{l}\text { Necessary } \\
\text { Operation }\end{array}$ & $\begin{array}{l}\text { Relational } \\
\text { term }\end{array}$ \\
\hline $\begin{array}{l}\text { 1. At BP, gas sells for } \$ 1.13 \text { per gallon. Gas at } \\
\text { Speedway is } 5 \text { cents more per gallon than gas at BP. } \\
\text { How much does } 5 \text { gallons of gas cost at Speedway? }\end{array}$ & 2-step & Consistent & Addition & 5 cents more \\
\hline $\begin{array}{l}\text { 2. At Kroger, a pound of pears cost } \$ 1.16 \text {. That is } 15 \\
\text { cents less per pound than at Walmart. How much } \\
\text { does } 5 \text { pounds of pears cost at Walmart? }\end{array}$ & 2-step & Inconsistent & addition & 15 cents less \\
\hline $\begin{array}{l}\text { 3. At BP, gas sells for } \$ 1.13 \text { per gallon. Gas at } \\
\text { Speedway is } 5 \text { cents less per gallon than gas at BP. } \\
\text { How much does } 5 \text { gallons of gas cost at Speedway? }\end{array}$ & 2-step & Consistent & Subtraction & 5 cents less \\
\hline $\begin{array}{l}\text { 4. At Meijers a pound of sugar costs } 89 \text { cents. That is } \\
20 \text { cents more per pound than at Walmart. How } \\
\text { much do } 5 \text { pounds of sugar cost at Walmart? }\end{array}$ & 2-step & Inconsistent & Subtraction & $\begin{array}{l}20 \text { cents } \\
\text { more }\end{array}$ \\
\hline $\begin{array}{l}\text { 5. Mary runs about } 6 \text { miles per week. Sandy runs } 3 \\
\text { times as many miles per week as Mary. How far does } \\
\text { Sandy run in a week? }\end{array}$ & 1-step & Consistent & Multiplication & $\begin{array}{l}3 \text { times as } \\
\text { many }\end{array}$ \\
\hline $\begin{array}{l}\text { 6. The local farm sells about } 15 \text { watermelons each day } \\
\text { during the summer. The supermarket sells } 3 \text { times as } \\
\text { many as the farm stand a day. How many } \\
\text { watermelons does the supermarket sell in } 5 \text { days? }\end{array}$ & 2-step & Consistent & Multiplication & $\begin{array}{l}3 \text { times as } \\
\text { many }\end{array}$ \\
\hline $\begin{array}{l}\text { 7. Joe runs } 6 \text { miles a week. He runs } 1 / 3 \text { as many } \\
\text { miles a week as Ken does. How many miles does } \\
\text { Ken run in a week? }\end{array}$ & 1 -step & Inconsistent & Multiplication & $1 / 3$ as many \\
\hline $\begin{array}{l}\text { 8. Sam's Grocery sells } 180 \text { eggs a day. That is } 1 / 3 \text { as } \\
\text { many eggs as Mike's Grocery sells a day. How many } \\
\text { eggs does Mike's Grocery sells in } 3 \text { days? }\end{array}$ & 2-step & Inconsistent & Multiplication & $1 / 3$ as many \\
\hline $\begin{array}{l}\text { 9. Donatos sells } 120 \text { regular pizza pies a day. Pizza } \\
\text { Hut sells } 1 / 3 \text { as many regular pies as Donatos in a } \\
\text { day. How many regular pizza pies does Pizza Hut } \\
\text { sell in a day? }\end{array}$ & 1 -step & Consistent & Division & $1 / 3$ as many \\
\hline $\begin{array}{l}\text { 10. Kroger sells } 50 \text { pounds of potatoes a day. } \\
\text { Meijers sells } 1 / 5 \text { as many potatoes as Kroger does in } \\
\text { a day. How many pounds of potatoes does Kroger } \\
\text { sell in } 4 \text { days? }\end{array}$ & 2-step & Consistent & Division & $1 / 5$ as many \\
\hline $\begin{array}{l}\text { 11. Last year the sixth grade sold } 125 \text { raffle tickets } \\
\text { each day. That is } 5 \text { times as many tickets as the fifth } \\
\text { grade sold per day. How many tickets did the fifth } \\
\text { grade students sell in a day? }\end{array}$ & 1 -step & Inconsistent & Division & $\begin{array}{l}5 \text { times as } \\
\text { many }\end{array}$ \\
\hline $\begin{array}{l}\text { 12. Kroger sells } 120 \text { bottles of water a day. That is } 2 \\
\text { times as many bottles as Giant's sells in a day. How } \\
\text { many bottles of water does Giant's sell in } 5 \text { days? }\end{array}$ & 2-step & Inconsistent & Division & $\begin{array}{l}2 \text { times as } \\
\text { many }\end{array}$ \\
\hline
\end{tabular}

\section{Procedures}

Preparation. To gain trust, before conducting this study, the first researcher met with the students and asked them what language they prefer to use-ASL or Signed English. She also observed them in classes several times and interacted with them after school using ASL. The participants and their math teacher, who was deaf, reported using a signed language (American Sign Language) as their primary or preferred language in school. Students were individually tested in a quiet room located in the library. 
Each student was instructed to follow the directions that were signed and then the directions were presented in the written form to ensure that all students had access in both languages. All students were instructed to write down all of the calculations they used while solving each word problem so the researcher could see their work. They were also informed that the researcher could not answer any questions related to solutions while working on the word problems.

To ensure that students understood the directions, the researcher conducted a practice session with two word problems, which were not compare word problems. Additionally, if a student left blank a problem, then the researcher asked the student why she/he left the problem blank. If a student forgot to write the process of solving the problem, the researcher provided a reminder. After completing the practice session, a set of 16 word problems were given to each student. The entire session took approximately 20-30 minutes to complete.

Scoring. The participants' written responses on the 12 word problems were analyzed to determine the number of correct responses and the types of errors. Each solution was scored as correct if both the numerical answer and procedures were correct or was scored as incorrect if either the numerical answer or procedures were incorrect. If there were several instances of a type of error, only the first error of a type was recorded so that multiple errors of the same kind were counted only once (Kelly et al., 2003). Additionally, incorrect problems were further analyzed and categorized with respect to error types adapted from the work of Pape (2003) and Kelly et al. (2003). These error categories are related to the DHH students' learning about compare word problems in that they show the students' thinking and what barriers they face.

In the present study, the following seven types of errors were identified:

1. Linguistic error: Students were unable to understand and solve the problem, and their solution steps did not make sense or solution plans were incorrect although the students had the ability to compute arithmetic operations (e.g., addition, subtraction, multiplication, and division).

2. Reversal error: Students used the opposite arithmetic operations to solve the problems. That is, students subtracted when the correct operation was addition; they added when the correct opera- tion was subtraction; or they used multiplication instead of division or division instead of multiplication.

3. Computation error: Students produced computation errors in one- or two-step problems, or they did not copy a number correctly for the computation procedure.

4. Fraction error: Students were unable to compute the problem that required fraction arithmetic operations. For example, students were unable to compute the fraction.

5. Goal-monitoring error: Students omitted one of the two computational steps in the two-step solution problems.

6. Multiple errors: Students committed the following errors more than once.

- solution steps were incorrect or omitted

- solution plans were incorrect

- computation errors occurred

- solution steps did not make sense

7. Problem left Blank: Students indicated an inability to solve the problem after reading it.

\section{Data Analytic Plan}

A large randomized sample is always desirable to obtain powerful results. However, when only smaller size samples are available, a t-test can be used if the effect size is large (deWinter, 2013). In the present study, the paired t-test was used to examine the effect of the consistency effect hypothesis. The number of correct responses and types of errors were documented, using Pape's (2003) rubric. A series of pair t-tests were run, setting the alpha level at .05.

\section{RESULTS}

\section{Word Problem Scores}

Thirteen students worked on 12 word problems, including 6 consistent language problems and 6 inconsistent language problems, resulting in a total of 151 (13 participants x 12 word problems - 5 problems left blank) written responses. Overall, the results indicated that approximately $65 \%$ of consistent language problems were solved. Participants produced significantly more correct solutions on the consistent language problems than on inconsistent language problems (see Table 5). The effect size was .81 and is considered large Cohen (1988). 
Table 5. The Frequency and Percentages of Problem-solving Success and Error Types for Consistent Language and Inconsistent Language Word Problems

\begin{tabular}{lccc}
\hline Types of errors & $\begin{array}{c}\text { 6 Consistent Language Problems } \\
\text { Frequency } \\
\text { (percentage) }\end{array}$ & $\begin{array}{c}\text { 6 Inconsistent Language Problems } \\
\text { Frequency } \\
\text { (percentage) }\end{array}$ & $\begin{array}{c}\text { Total } \\
\text { Frequency } \\
\text { (percentage) }\end{array}$ \\
\hline Correct solutions & $51^{*}$ & $8^{*}$ & 59 \\
Linguistics error & $(65.38 \%)$ & $(10.26 \%)$ & $(37.82)$ \\
Reversal error & $(10.26)$ & $(11.54)$ & $(10.90)$ \\
Computation error & 3 & $46^{*}$ & 49 \\
& $(3.85)$ & $(58.97)$ & $(31.41)$ \\
Fraction error & 2 & 0 & 2 \\
& $(2.56)$ & $(0)$ & $(1.28)$ \\
Goal monitoring error & 3 & 2 & $(3.21)$ \\
Left problem blank & $(3.85)$ & $2.56)$ & 7 \\
& 5 & $(2.56)$ & $(4.49)$ \\
Multiple errors & $(6.41)$ & 2 & 5 \\
Total & 3 & $(2.56)$ & $(3.21)$ \\
& $(3.85)$ & 9 & 12 \\
& $(3.85)$ & $(11.54)$ & $(7.69)$ \\
\hline
\end{tabular}

*significant at the .05 level

\section{Types of Errors}

Approximately $65 \%$ of consistent language problems were solved correctly whereas only $10 \%$ of inconsistent language problems were correctly solved. To identify what kind of problems students most correctly solved, an individual item analysis was conducted. Multiplication and addition problems were the most correctly used operations on consistent language problems. Students solved only a few of the inconsistent language problems with the multiplication, subtraction, and division operations, and no student solved an inconsistent language problem that requires an addition operation. To solve the inconsistent language addition problems (e.g., At Kroger, water sells for $\$ 1.11$ per gallon. This is 4 cents less per gallon than water at HEB.) with the relational term "less", the operation called for addition, not subtraction. Thus, to obtain the correct answer, students must use their inference skills and reorganize mentally the relational sentence to select the arithmetic operation needed for the correct answer.

The types of errors students committed while solving the word problems were also analyzed, based on Pape's (2003) rubric. A total of 92 errors made by the students except for problem left blank $(n=5)$ were identified. The decision was made to label leaving a blank as an error after we instructed the students to finish all word problems. The most common types of errors were reversal errors for both problems $(n=49,31.41 \%)$, linguistic errors $(n=17,10.90 \%)$, and multiple errors $(n=$ $12,7.69 \%$ ). In contrast, the fewest types of errors were goal monitoring errors $(n=7,4.49 \%)$, fraction error $(\mathrm{n}=5,3.21 \%)$, and computation errors $(\mathrm{n}=2,1.28$ $\%$ ). In addition, the errors students committed were different according to the types of problems (i.e., consistent language compared to inconsistent language word problems). For example, linguistics $(\mathrm{n}=8 ; 10.26 \%)$ and goal monitoring errors $(n=5 ; 6.41 \%)$ were greater for the consistent language problems. However, with inconsistent language problems, the majority of the errors were reversal errors $(\mathrm{n}=46,58.97 \%)$ and linguistics and multiple errors $(n=9 ; 11.54 \%)$, respectively (See Table 5). The reversal errors generated by students resulted from misunderstanding of the relational statements that are inconsistent with the required arithmetic operations or from the use of key words rather than attempts to understand what the problem was asking of them. 
Lexically Marked vs. Unmarked Relational Terms

To examine the effect of lexical markedness on inconsistent language problems, the reversal errors in inconsistent language problems with positive unmarked relational terms (e.g., more, taller, as much) were compared to reversal errors in inconsistent language problems with negative marked relational terms (e.g., less, $1 / \mathrm{n}$ as much). There were no differences in the number of reversal errors between inconsistent language problems that required addition and multiplication operations (e.g., marked terms, 30.77\%) and inconsistent language problems that required subtraction and division operations (e.g., unmarked terms, $33.33 \%$ ). See Table 6.

Table 6. Percentages for Reversal Errors and Correct Responses Relative to the Lexical Marked Terms

Marked Terms in IL Problems
(more difficult to comprehend)

IL addition

IL multiplication

17.95

$.08(.19)$
Unmarked Terms in IL Problems (easier to comprehend)

\begin{tabular}{ccccccc}
$\begin{array}{c}\text { Reversal Error } \\
\text { (\%) }\end{array}$ & 12.82 & 17.95 & 30.77 & 8.97 & 24.36 & 33.33 \\
$\begin{array}{c}\text { Success rate } \\
\text { M (SD) }\end{array}$ & $0(0)$ & $.08(.19)$ & $.05(.13)$ & $.23(.44)$ & $.08(.19)$ & $.13(.22)$ \\
\hline
\end{tabular}

Note: $\mathrm{M}=$ mean; $\mathrm{SD}=$ standard deviation

$\mathrm{IL}=$ inconsistent language

The success rate of problem solving between inconsistent language and marked language and inconsistent and unmarked language were compared to examine if the lexically marked terms affected performance on inconsistent language word problems. The results indicated that there was no statistically significant difference between both groups, although participants produced slightly more correct solutions for inconsistent language problems when the relational terms were unmarked $(\mathrm{M}=.13, \mathrm{SD}$ $=.22)$ as compared to marked $(\mathrm{M}=.05, \mathrm{SD}=.13)$ items, $\mathrm{t}(12)=1.39, \mathrm{p}=.34$. Figures 1 and 2 present percentages for reversal errors and the success rates for lexically marked terms as compared to the lexically unmarked terms for the inconsistent language problems.

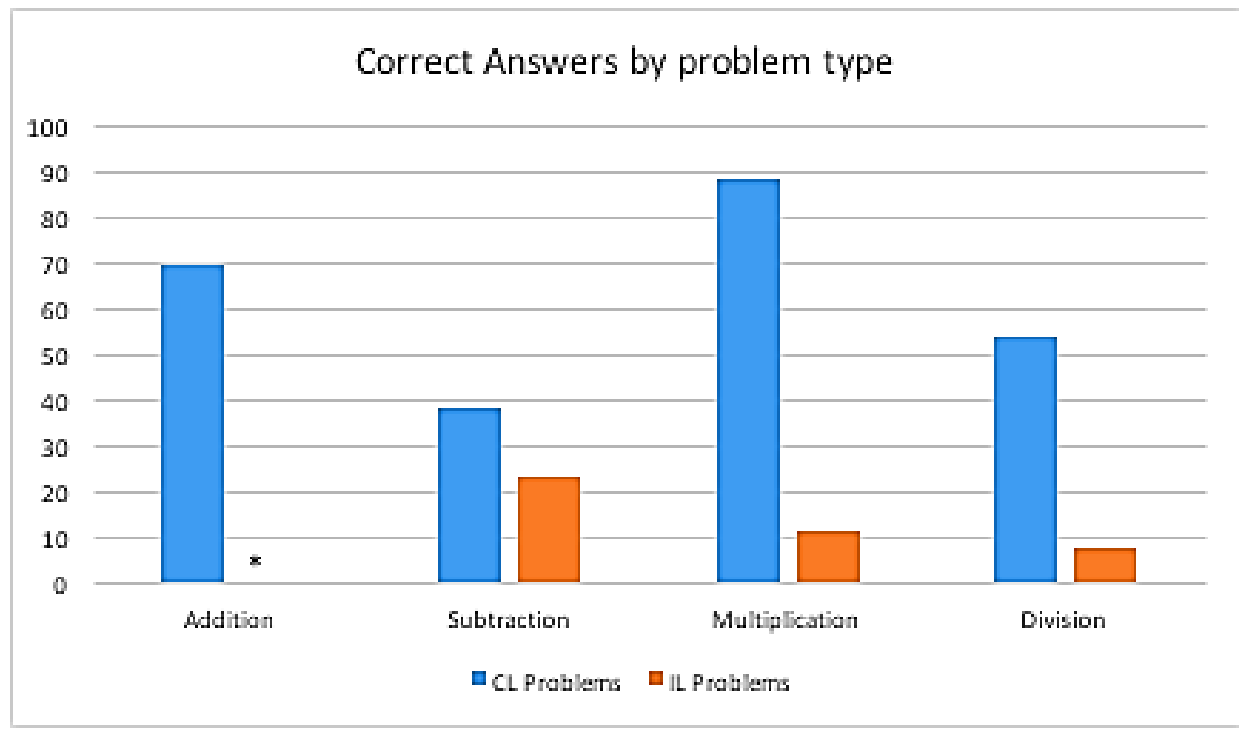

Figure 1 Correct Answers by Problem Type

Note: $\quad \mathrm{CL}=$ consistent Language;

$\mathrm{IL}=$ inconsistent Language

*: zero score 


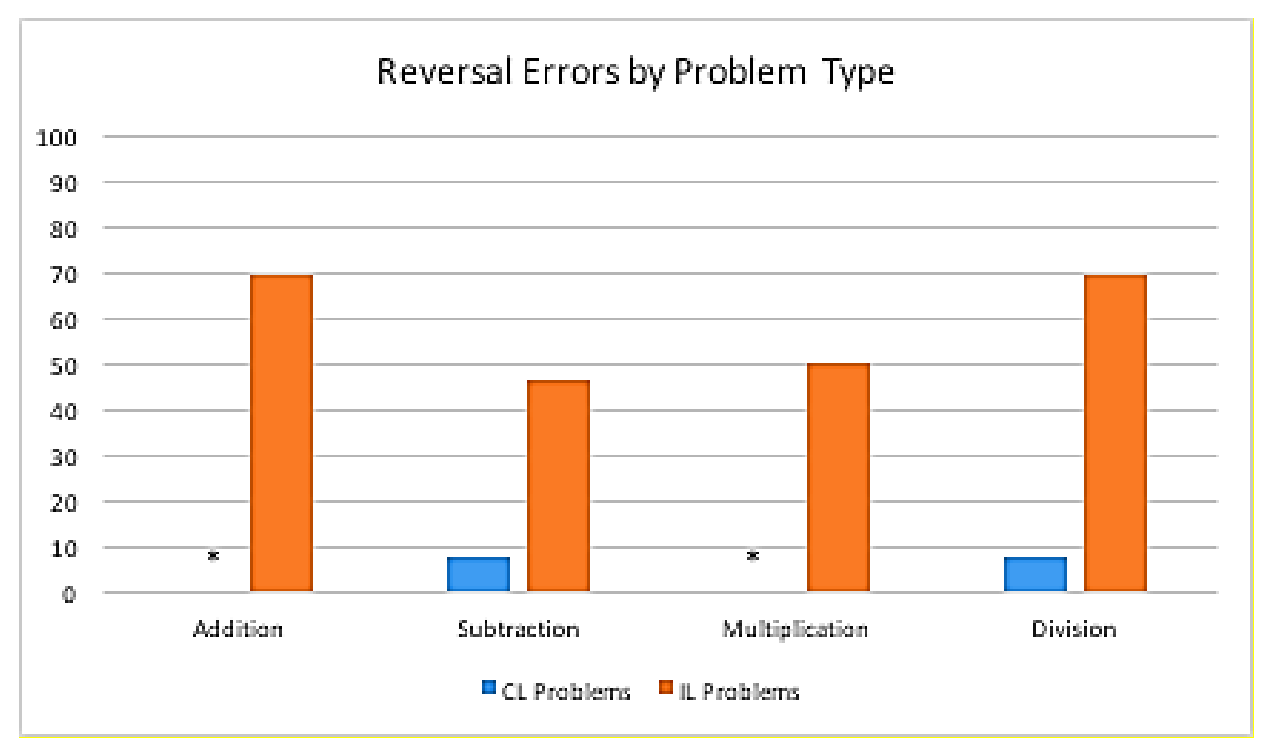

Figure 2 Reversal Errors by Problem Type

Note: $\quad \mathrm{CL}=$ consistent Language

$\mathrm{IL}=$ inconsistent Language

*: zero score

\section{Fraction-of-a-Number Relational Terms}

Participants' performances on word problems with and without a fraction-of-a-number relational term were analyzed to examine if there were any differences between performance on word problems with such relational terms and without such relational terms. The findings indicated that participants solved consistent language multiplication and inconsistent language division problems without a fraction-of-a-number word- ing $(\mathrm{M}=1.92, \mathrm{SD}=.64)$ significantly more correctly than consistent language division and inconsistent language multiplication problems with such wording (M $=1.31, \mathrm{SD}=.85), \mathrm{t}(12)=-2.31, \mathrm{p}<.05$. The findings demonstrate that a fraction-of-a number relational terms were more difficult and exerted more influence on students' problem-solving performance than did the lexically marked terms. The correct rates (percentages) of word problems with and without fraction-ofa-number relational terms are presented in Table 7.

Table 7. Percentages of Correct Responses for Fraction and Non-Fraction

\begin{tabular}{lcccccr}
\hline & FL & Fraction & & \multicolumn{2}{c}{ Non-Fraction } \\
& $\begin{array}{c}\text { IL } \\
\text { Division }\end{array}$ & Multiplication & & Total Multiplication & IL Division & Total \\
\hline Problem-Solving Success (\%) & 53.9 & 11.6 & 32.8 & 88.5 & 7.7 & 48.1 \\
\hline
\end{tabular}

Note: $\quad \mathrm{CL}=$ consistent language

$\mathrm{IL}=$ inconsistent language

\section{DISCUSSION}

DHH middle school students were administered a set of 12 compare word problems. Students correctly solved more compare word problems that have relational statements consistent with the arithmetic operations than word problems having relational statements that are inconsistent with the arithmetic operations. Therefore, these findings reveal that the consistency effect hypothesis is supported by the performance of DHH middle school students on compare word problems. Further, these results supporting the consistency effect hypothesis are robust across previous studies with $\mathrm{DHH}$ college students (Kelly et al., 2003), hearing college students (Lewis \& Mayer, 1987), hearing students in junior high (Pape, 2003), and hearing students in elementary grades (Verschaffel et al., 1992). These results also support the work of Ansell and Pagliaro (2006) and Pagliaro and Ansell (2012) who found that compare word problems were more difficult for DHH students than combine and change word problems. 
While slightly more reversal errors were made by DHH students on inconsistent language problems when the relations are negatively marked (e.g., less) compared to positively unmarked items (e.g., more), there was no significant difference between the two conditions. This finding confirms our second hypothesis and is counter to those of previous hearing and DHH studies which indicated that reversal errors for inconsistent language problems increased when the relational statements included negative marked terms (e.g., less, shorter, younger, and $1 / n$ as much) than those problems that included positive unmarked terms (e.g., more, taller, older, and $n$ as much) (Lewis \& Mayer, 1987; Pape, 2003; Verschaffel et al., 1992; for DHH college students, see Kelly et al., 2003).

That DHH junior high students in the present study produced more errors on word problems that contained fraction-of-a-number terms than with problems without such terms confirms our third hypothesis. This finding was expected given that it is well documented that DHH students lack a basic understanding of fractions. Previous studies reported that DHH students do not understand how to execute calculations with fractions nor do they have the understanding of other aspects of fractions such as order and equivalence (Titus, 1995). Students also have difficulties with concepts related to part to whole (Kelly \& Mousley, 2001; Markey et al., 2003), placement in order from smallest to largest (Mousley \& Kurz, 2015), comprehending the relationship between fractions and ratios (1:3 and 1:4) (Nunes \& Moreno, 2002), and understanding fractions embedded in compare word problems (Lee, 2010).

\section{LIMITATIONS AND FUTURE RESEARCH}

The students in the present study were from a residential school that used ASL and English. Future studies may want to enlarge the sample and include junior high students who are from oral backgrounds, total communication backgrounds, including those who use digital hearing aids and cochlear implants. A second limitation is the amount of time DHH students were given to read and solve the word problems. Future studies may provide more time to complete the word problems to examine the effects. A third limitation is that no assessment of sign language skills was obtained. Future research can address this limitation by utilizing a standardized sign language assessment, similar to that used by Ansell and Pagliaro (2006) and Pagliaro and Ansell (2012). A fourth limitation is the wide range of reading levels found among the 13 students. Two of the students had reading levels of 2.5 and 4.0, respectively, whereas the reading levels of the word problems were between $4^{\text {th }}$ and $5^{\text {th }}$ grade. A decision was made not to rewrite the compare word problems because this would invalidate the study since one of the foci was to examine relational language embedded in story problems. Future studies can match reading levels with the reading levels of the word problems more closely. A fifth limitation is the manner in which the errors were coded. It is possible for a student to make a reversal, computation, or goal-monitoring error within a fraction error, and these errors may be important because they may affect arriving at the correct answer. Future studies may help clarify this issue to determine how the fraction error code relates to the other error codes. Future studies may also provide more criteria for each error and add an independent coder to ascertain inter-rater coding reliability.

Future research may also explore the importance of teacher preparation in math areas, including math teaching state licensure given that multiple studies reported that many teachers are simply not prepared sufficiently in mathematical teaching (Corredor \& Calderon, 2010; Kelly et al., 2003; Pagliaro, 2015). Innovative interventions such as cognitively guided math instruction as recommended by Carpenter and his colleagues (2015) should be examined. The present study indicated that DHH students need modeling so they can develop visual mental representations of mathematical relationships.

The DHH students in previous studies (Ansell \& Pagliaro, 2006; Frostad \& Ahlberg, 1999; Kelly et al., 2003; Serrano Pau, 1995) became "stuck" as they focused on surface structure strategies such as numbers, key words, or trigger words, or translation strategies thinking that more always means addition and less always means subtraction, without using their inference skills to see what the story problem required. Alternatively, students may also be bypassing a meaningful approach and fall into translating the story word-by-word, thus missing on figuring out what the relational language meant. DHH students may benefit from teacher-talk that focuses on deep thinking about mental representations of mathematical relationships such as those suggested by Corredor and Calderon (2010). This mathematical "teacher-talk" must proceed beyond sign translation and lead the students into extended conversations about mathematical relationships such as those that the compare word problems pose. 
Teaming a CDI (Certified Deaf Interpreter) to work alongside of a signing teacher with mathematic training to provide not only linguistic support but also cognitive and math scaffolding to teach mental representations of arithmetic relational language using cognitively-guided instruction could be tested in future intervention studies.

Future researchers with DHH students examining compare word problems may want to explore other methodological protocols such as those used with hearing students to test the consistency effect hypothesis such as eye-tracking protocols (Hegarty et al., 1995; Hegarty et al., 1992), think-aloud or verbal reports (Pape, 1998, 2003), and retellings about solution steps (Verscharffel, 1994; Verschaffel et al., 1992).

\section{CONCLUSION}

Compare word problems are difficult to solve not only for DHH students, but for hearing students as well (Carpenter et al., 2015). But not all compare word problems are alike. Those with inconsistent language are more difficult to solve than those with consistent language (Lewis \& Mayer, 1987). And when fraction-of-a-number terms are added to the mix, they become even more difficult to solve because these problems contain linguistic forms that do not map onto the students' existing conceptual knowledge structures. As such, a student may understand part-to-whole set relations, but may not understand comparative verbal forms such as "If $\mathrm{X}$ is $1 / \mathrm{n}$ as many as $\mathrm{Y}$, how much is $\mathrm{X}$ ?" As the present study and other studies indicated, when providing word problems of any kind, DHH students may lack both mathematical conceptual and linguistic tools to solve them (Pagliaro, 2015; Pagliaro \& Kritzer, 2013).

This lack of mathematical conceptual tools for DHH students creates a "math gap" that starts as early as preschool (Ansell \& Pagliaro, 2006; Kritzer, 2009; Pagliaro \& Kritzer, 2013), follows them into elementary school (Zarfaraty et al., 2004), into middle school (Lee, 2010), and even into postsecondary education (Kelly \& Mouseley, 2001; Kelly et al., 2003). Not only has this "math gap" in achievement been documented in the United States (Traxler, 2000), but also, similar math gaps have been found globally with $\mathrm{DHH}$ students in Columbia, South America (Corredor \& Calderon, 2010), in Spain (Serrano Pau, 1995), in Norway (Frostad \& Ahlberg, 1999), and in England (Swanwick et al., 2005).

Linguistic difficulties also contribute to the "math gap." DHH students have problems with math terminology
(Serrano Pau, 1995), particularly relational terminology (Kidd et al., 1993; Zevenberger et al., 2001). These multiple meaning words take on new meanings when they occur in mathematical contexts (Paul, 2009). Linguistic challenges also extend beyond the word and phrase level to other syntactic structures such as pronominal reference (Swanwich et al., 2005) and question formation (Zevenberger et al., 2001). Paul (2009) provided a robust discussion of DHH readers' challenges not only with question formation but also pronoun usage, determiner usage, conjoined sentences, relative clauses, and passive voice. These specific English structures that DHH students find problematic are abundantly found in junior high math textbooks and on practice tests. See, for example, the State of Texas Assessment of Academic Readiness (STAAR) tests (https://tea.texas.gov/student.assessment/STAAR_Released_Test_Questions/). Even when word problems are translated into a signed language, this does not necessarily lead to comprehension of math concepts (Ansell \& Pagliaro, 2001; Corredor \& Cladker, 2010; Pagliaro \& Ansell, 2012). The translation of compare word problems may be necessary for signing DHH students, but it is not sufficient. DHH students were found to overuse a "counting strategy" where they focused on the quantity (number) and continued to count a sequence to the second quantity (number), then decide on an arithmetic operation based on a "key" or "trigger" word (e.g., more means addition; less means subtraction). This counting strategy did not result in correct answers, but may have emphasized that teachers focus too much on procedural operations rather than assisting the students into "thinking through" the story problem.

As such, the difficulties DHH students in junior high face are more extensive than arithmetic conceptual understandings, procedural mistakes, linguistic terminology or even their proficiency in a signed language. DHH students as shown by their performance in the present study simply did not know how to "think like a math person" who has a mental representation of relational language embedded in the compare word problems. Instead, as found in the literature, DHH students attacked word problems using surface structure strategies such as focusing on key or trigger words or on the numbers, used their own schema, and chose operations based on key words rather than using inference skills to arrive at the correct solution. Until teachers figure out how to teach these underlying mental mathematical representations of compare word problems through cognitively guided and engaged lessons, DHH students will continue to struggle. 


\section{REFERENCES}

Ansell, E., \& Pagliaro, C. M. (2001). Effects of a signed translation on the type of difficulty of arithmetic story problems. Focus on Learning Problems in Mathematics, 23, 41-69.

Ansell, E., \& Pagliaro, C. M. (2006). The relative difficulty of signed arithmetic story problems for primary level deaf and hard-of-hearing students. Journal of Deaf Studies and Deaf Education, 11, 153-170. doi: 10.1093/deafed/enj030

Carpenter, T., Corbitt, M. K., Kepner, H. S., Linquist, M. M., \& Reys, R. E. (1980). Solving verbal problems: Results and implications from national assessment. Arithmetic Teacher, 28(1), 8-12.

Carpenter, T., Fennema, E., Franke, M., Levi, U. \& Empson, S. (2015). Children's mathematics: Cognitively guided instruction. Second edition. New Hampshire, Heinnemann.

Chall, J. S., \& Dale, E. (1995). Readability revisited, the new Dale-Chall readability formula. Cambridge, MA: Brookline Books.

Cohen, J. (1988). Statistical power analysis for the behavioral sciences. $2^{\text {nd }}$ edition, Mahweh, New Jersey: Lawrence Erlbaum Associates.

Common Core State Standards Initiative. (2013). Retrieved from http://www.corestandards.org/Math/

Corredor, L. \& Calderón, D. (2010). Bilingualism of Colombian deaf children in the teaching-learning of mathematics in the first year of elementary school. Colombian Applied Linguistics Journal, 12(2), 9-24.

Cummins, D. D., Kintsch, W., Reusser, K., \& Weimer, R. (1988). The role of understanding insolving wordproblems. Cognitive Psychology, 20, 405-438. doi:10.1016/00100285(88)90011-4.

deWinter, J. (2013). Using the student's t-test with extremely small sample sizes. Practical assessment research and evaluation, 18(10), 1-12

Etikan, I., Musa, S. A., \& Alkassim, R. S. (2016). Comparison of convenience sampling and purposive sampling. American Journal of Theoretical and Applied Statistics, 5(1), 1-4.

Frostad, P., \& Ahlberg, A. (1999). Solving story-based arithmetic problems: Achievement of children with hearing impairment and their interpretation of meaning. Journal of Deaf Studies and Deaf Education, 4, 283-293. doi: 10.1093/deafed/4.4.283

Hegarty, M., Mayer, R., \& Green, C. (1992). Comprehension of arithmetic word problems: Evidence from students' eye fixations. Journal of Educational Psychology, 84, 76-84. doi: 10.1037/0022-0663.84.1.76.

Hegarty, R. E., Mayer, E., \& Monk, C. (1995). Comprehension of arithmetic word problems: A comparison of successful and unsuccessful problem solvers, Journal of Educational Psychology, 87, 18-32. doi:10.1037/0022-0663.87.1.18

Hyde, M., Zevenbergen, R., \& Power, D. (2003). Deaf and hard of hearing students' performance on arithmetic word problems. American Annals of the Deaf, 148, 56-64. doi: 10.1353/aad.2003.0003

Kelly, R., Lang, H., Mousley, K., \& Davis, S. (2003). Deaf college students' comprehension of relational language in arithmetic compare problems. Journal of Deaf Studies and Deaf Education, 8, 120-132. doi: 10.1093/deafed/ eng006
Kelly, R., Lang, H., \& Pagliaro, C. (2003). Mathematics word problem solving for deaf students: A survey of practices in grades 6-12. Journal of Deaf Studies and Deaf Education, 8, 104-119. doi: 10.1093/deafed/eng007

Kelly, R., \& Mousley, K. (2001). Solving word problems: More than reading issues for deaf students. American Annals of the Deaf, 146, 251-262. doi: 10.1353/aad.2012.0088

Kidd, D. H., Madsen, A. L., \& Lamb, C. E. (1993). Mathematics vocabulary: Performance of residential deaf students. School Science and Mathematics, 93, 418-421. doi: 10.1111/j.1949-8594.1993.tb12272.x

Kritzer, K. (2009). Barely started and already left behind: A descriptive analysis of the mathematics ability demonstrated by young deaf children. Journal of Deaf Studies and Deaf Education, 14, 409-421. doi: 10.1093/deafed/enp015

Lee, C. (2010). Middle school deaf students' problem-solving behaviors and strategy use. (Unpublished doctoral dissertation). The Ohio State University, Columbus, OH, U.S.A.

Lewis, A. B., \& Mayer, R. (987). Students' miscomprehension of relational statements in arithmetic word problems. Journal of Educational Psychology, 79, 363-371. doi: 10.1037/0022-0663.79.4.363

Markey, C., Power, D., \& Booker, G. (2003). Using structured games to teach early fraction concepts to students who are deaf and hard of hearing. American Annals of the Deaf, 148(3), 251-258.

Mousley, K., \& Kurz, C. (2015). Pre-college deaf students' understanding of fractional concepts: What we know and what we do not know. Journal of Science Education for Students with Disabilities, 18(1), 44-65.

Nunes, T., \& Moreno, C. (2002). An intervention program for promoting deaf pupils' achievement in mathematics. Journal of Deaf Studies and Deaf Education, 7(2), 120133.

Pagliaro, C. (2010). Mathematics instruction and learning of deaf and hard of hearing students: What do we know? Where do we go? (pp. 156-171). In M. Marschark\& P. Spencer (Eds.). The Oxford handbook of deaf studies, language, and education. Vol. 2. New York: Oxford University Press.

Pagliaro, C. M. (2015). Developing numeracy in individuals who are deaf and hard of hearing. In H. Knoors and M. Marschark (Eds.). Educating deaf learners: Creating a global evidence base, (pp.173-195). New York: Oxford University Press

Pagliaro, C., \& Ansell, E. (2012). Deaf and hard of hearing students' problem-solving strategies with signed arithmetic story problems. American Annals of the Deaf, 156, 438458. doi: 10.1353/aad.2012.1600

Pagliaro, C., \& Kritzer, K. (2013). The math gap: A description of the mathematics performance of preschool-aged deaf/ hard-of-hearing children. Journal of Deaf Studies and Deaf Education, 18, 139-160. doi:10.1093/deafed/ens070

Pape, S.J. (1998). Components of a reading comprehension model of mathematical problem solving and their relation to problem solving success (Unpublished doctoral dissertation). The City University of New York, New York, NY.

Pape, S. (2003). Compare word problems: Consistency hypothesis revisited. Contemporary Educational Psychology, 28, 396-421. doi: 10.1016/S0361-476X(02)00046-2 
Paul, P. V. (2009). Language and deafness (4th ed.). Sudbury, MA: Jason \& Bartlett.

Qi, S. \& Mitchell, R. (2012). Large-scale academic achievement testing of deaf and hard-of-hearing students: past, present, and future. Journal of Deaf Studies and Deaf Education, 17, 1-18. doi: 10.1093/deafed/enr028

Serrano Pau, C. (1995). The deaf child and solving problems of arithmetic: The importance of comprehensive reading. American Annals of the Deaf, 140, 287-294. doi: 10.1353/ aad.2012.0599

Swanwick, R., Oddy, A., \& Roper, T. (2005). Mathematics and deaf children: An exploration of barriers to success. Deafness and Education International, 7, 1-11. doi: 10.1002/ dei. 20

The state of Texas assessment of academic readiness (STAAR). Retrieved from https://tea.texas.gov/student.assessment/ STAAR_Released_Test_Questions/

Titus, J. C. (1995). The concept of fractional number among deaf and hard of hearing students. American Annals of the Deaf, 140, 255-263. doi: 10.1353/aad.2012.0582

Traxler, C. B. (2000). Measuring up to performance standards in reading and mathematics: Achievement of selected deaf and hard-of-hearing students in the national norming of the 9th Edition Stanford Achievement Test. Journal of Deaf Studies and Deaf Education, 5(4), 337-348.
Verschaffel, L. (1994). Using retelling data to study elementary school children's representationsand solutions of compare problems. Journal for Research in Mathematics Education, 25, 141-165. doi: 0.2307/749506

Verschaffel, L., de Corte, E., \& Pauwels, A. (1992). Solving compare problems: An eye movement test of lewis and Mayer's consistency hypothesis. Journal of Educational Psychology, 84, 85-94. doi: 10.1037/0022-0663.84.1.85

Zarfaty, Y., Nunes, T., \& Bryant, P. (2004). The performance of young deaf children in spatial and temporal number tasks. Journal of Deaf Studies and Deaf Education, 9(3), 315326.

Zevenbergen, R., Hyde, M., \& Power, D. (2001). Language, arithmetic word problems, and deaf students: Linguistic strategies used to solve tasks. Mathematics Education Research Journal, 13, 204-218. doi:10.1007/BF032171 